\title{
Article \\ Application of Biochar Functionalized with Layered Double Hydroxides: Improved Plant Growth Performance after Use as Phosphate Adsorbent
}

\author{
Jittrera Buates and Tsuyoshi Imai *
}

check for updates

Citation: Buates, J.; Imai, T.

Application of Biochar Functionalized with Layered Double Hydroxides: Improved Plant Growth Performance after Use as Phosphate Adsorbent. Appl. Sci. 2021, 11, 6489. https:// doi.org/10.3390/app11146489

Academic Editor: Jorge Paz-Ferreiro

Received: 17 June 2021

Accepted: 13 July 2021

Published: 14 July 2021

Publisher's Note: MDPI stays neutral with regard to jurisdictional claims in published maps and institutional affiliations.

Copyright: (c) 2021 by the authors. Licensee MDPI, Basel, Switzerland. This article is an open access article distributed under the terms and conditions of the Creative Commons Attribution (CC BY) license (https:/ / creativecommons.org/licenses/by/ $4.0 /)$.
Division of Environmental Engineering, Graduate School of Sciences and Technology for Innovation, Yamaguchi University, Yamaguchi 755-8611, Japan; g501wd@yamaguchi-u.ac.jp

* Correspondence: imai@yamaguchi-u.ac.jp

\begin{abstract}
The objective of this study was to verify the feasibility of using biochar, functionalized with layered double hydroxides, as a fertilizer after its use in phosphate treatment (P-BC-LDHs). It was conducted with several levels of P-BC-LDHs using seed germination and early growth assays of lettuce (Lactuca sativa L.). The application of P-BC-LDHs resulted in successful seedling emergence, with an excellent germination capacity of over $96 \%$ for all treatments. However, compared to the controls, P-BC-LDHs did not provide favorable seedling traits. In contrast, in the latter experiments, lettuce cultivated under mixtures with P-BC-LDHs, particularly at an application rate of $2.5 \%(w / w)$, displayed superior growth quality to those under non-treated conditions. The length of lettuce shoots and roots from this optimal dosage were increased by at least $24 \%$ compared to untreated samples. A 17\% reduction in biomass yield was observed for the samples from non-supplemented substrates. The nutrient release profiles showed that P-BC-LDHs were capable of slowly supplying phosphorus, thereby increasing the long-term nutrient availability for plants. The findings reported here provide important insights into these materials and confirm that P-BC-LDHs can be used for agricultural purposes after phosphate remediation applications. The results of this study provide constructive information to facilitate the implementation of biochar-based LDH composites for sustainable phosphate removal and recovery.
\end{abstract}

Keywords: biochar; layered double hydroxides; nutrient recycling; phosphate recovery; fertilizer; plant growth

\section{Introduction}

The intensification of global food production has led to renewed interest in fertilizer development that has better application efficiency in order to achieve long-term food security. Phosphate is an essential nutrient and a non-substitutable constituent of agricultural fertilizers, and non-renewable phosphate rock, the world's major resource for phosphate fertilizer production, is becoming progressively depleted. Furthermore, phosphate overloads in aquatic environments can promote the excessive production of photosynthetic aquatic microorganisms and eventually contribute to undesirable eutrophication. Therefore, phosphate recovery from secondary sources, particularly in wastewater, is a desirable alternative for achieving sustainable phosphate supplies and simultaneously reducing detrimental environmental impacts.

Adsorption is a well-established technology for rapid, highly efficient, uncomplicated phosphate removal and recovery from phosphate-contaminated water. However, the major challenge of this technique is to design environmentally friendly, low-cost, and high-capacity adsorbents that enable an economical and simple pathway for phosphate recovery [1]. A successful attempt was made in a previous study conducted by the present authors, whereby the development of waste materials as an innovative phosphate adsorbent with rice straw-derived biochar was functionalized with layered double hydroxides 
(BC-LDHs). The composite demonstrated cost effectiveness and a sustainable solution for phosphate control [2]. As well as playing a role in phosphate remediation, BC-LDHs have the potential to be directly reutilized as a source of phosphate after a period of use as an adsorbent, contributing to improved phosphate recovery from contaminated water for agricultural reuse.

Biochar is an organic carbon-rich material obtained from the pyrolysis of biomass under high-temperature and low-oxygen conditions [3]. The resultant biochar has a large specific surface area, a porous microstructure, and abundant surface functional groups [4]. Moreover, biochar usually contains high concentrations of bioavailable nutrients, such as carbon, nitrogen, hydrogen, and some trace elements, including potassium, calcium, sodium, and magnesium [5]. These remarkable properties of biochar have been identified as the main reasons for improved soil properties and crop productivity [3,6,7]. According to Hameeda et al. [8], the positive effect of wood-derived biochar on the water retention capacity of soil, which in turn promoted root growth during the initial growth stage, greatly contributed to high tomato biomass and yield production. In vegetable studies, William and Qureshi [9] reported that biochar produced from horse manure and dried grass could be a suitable replacement or alternative to inorganic fertilizers. In addition, layered double hydroxides (LDHs), a class of layered compounds, have attracted considerable attention for agricultural applications. The structure of LDHs consists of positively charged mixed metal hydroxide sheets, which are balanced by the intercalation of anions in the hydrated interlayer regions. The general chemical formula of LDHs is denoted as $\left[\mathrm{M}^{2+}{ }_{1-\mathrm{x}} \mathrm{M}^{3+}{ }_{\mathrm{x}}(\mathrm{OH})_{2}\right]^{\mathrm{x}+}\left(\mathrm{A}^{\mathrm{n}-}\right)_{\mathrm{x} / \mathrm{n}} \cdot \mathrm{mH}_{2} \mathrm{O}$, where $\mathrm{M}^{2+}$ and $\mathrm{M}^{3+}$ represent the divalent and trivalent cations, respectively, $\mathrm{A}^{\mathrm{n}-}$ is the anion in the interlayer for charge compensation, and $x$ is equal to the molar ratio of $\mathrm{M}^{3+} /\left(\mathrm{M}^{2+}+\mathrm{M}^{3+}\right)$ [10]. LDHs have recently become popular for treating anionic pollutants because of their strong positive surface charge and exchangeable interlayer anions [11]. Alternatively, some studies have indicated that LDHs have been used as agrochemicals or fertilizers because of their potential to control herbicide and nutrient losses [12-14].

Despite the significant attention paid to phosphate adsorption onto BC-LDHs and the individual implementation of these materials - namely, biochar and LDHs-in agricultural practices, there have been no extensive investigations into the role of such composites after their adsorption in plant systems. In our previous study [2], we evaluated the preparation of various types of BC-LDH composites, with an emphasis on the influence of biochar quantities and fabrication methods on their phosphate adsorption characteristics, and especially their adsorption mechanisms. However, we were unable to confirm the potential of reusing these nutrient-loaded materials as fertilizers. Although high-efficiency adsorbents have been developed for sustainable and affordable phosphate treatments, we still face the major challenge of the efficient utilization of this reclaimed phosphate nutrient. This is critical in preventing the depletion of limited phosphate resources. Considering these issues, we propose the novel idea of the direct utilization of post-adsorption BC-LDHs as agricultural fertilizers. In this ongoing study, a new class of fertilizer products was obtained from phosphate-containing BC-LDHs (P-BC-LDHs), and their effect on plants was assessed through a series of experiments that compared several P-BC-LDH application rates. To the best of our knowledge, the present study is the first to evaluate the effect of different dosages of P-BC-LDHs on plant growth by observing the seed germination and early growth responses of lettuce (Lactuca sativa L.). Additionally, the solubility behavior of phosphorus and magnesium nutrients in P-BC-LDHs and aluminum were compared for the first time. This study contributes toward filling knowledge gaps in this area as its results broaden the understanding of the actual interaction between P-BC-LDHs and plants, as well as determining the optimal dosage for its potential reuse as a beneficial phosphate fertilizer. 


\section{Materials and Methods}

\subsection{Materials}

Aluminum chloride hexahydrate $\left(\mathrm{AlCl}_{3} \cdot 6 \mathrm{H}_{2} \mathrm{O}, 98 \%\right)$, magnesium chloride hexahydrate $\left(\mathrm{MgCl}_{2} \cdot 6 \mathrm{H}_{2} \mathrm{O}, 98 \%\right)$, sodium hydroxide $(\mathrm{NaOH}, 97 \%)$, potassium dihydrogen phosphate $\left(\mathrm{KH}_{2} \mathrm{PO}_{4}, 99.5 \%\right)$, and other reagents used for the synthesis and analysis of P-BCLDHs were purchased from Wako Pure Chemical Industries, Ltd. (Osaka, Japan). All chemicals used in this study were of analytical grade. The deionized water used for all experimental procedures was obtained from Eyela Still Ace SA-2100E (Tokyo Rikakikai Co., Ltd., Tokyo, Japan). Rice straw, collected from a local agricultural field in Yamaguchi, Japan, was selected as the raw material for biochar production. The feedstock was washed with deionized water and then oven-dried at $100{ }^{\circ} \mathrm{C}$ for $24 \mathrm{~h}$. The dried rice straw was crushed into powder, sieved to a uniform size of $0.2 \mathrm{~mm}$, and stored in airtight plastic containers for later use. The lettuce seeds (Lactuca sativa L.) and peat-based growing media used in this study were purchased from a local market in Yamaguchi, Japan. The physicochemical characteristics of the growing substrates are specified in the Supplementary Materials.

\subsection{Preparation of $P-B C-L D H s$}

Rice straw loaded with LDHs (RS-LDHs) was initially fabricated through the chemical coprecipitation of aluminum and magnesium on the biomass surface, followed by pyrolysis under optimal conditions. To synthesize RS-LDHs, $\mathrm{AlCl}_{3} \cdot 6 \mathrm{H}_{2} \mathrm{O}(0.01 \mathrm{~mol})$ and $\mathrm{MgCl}_{2} \cdot 6 \mathrm{H}_{2} \mathrm{O}(0.03 \mathrm{~mol})$ were dissolved in $100 \mathrm{~mL}$ of deionized water, and $10 \mathrm{~g}$ of rice straw powder was simultaneously immersed in a solution with $\mathrm{pH}$ maintained at $10 \pm 0.5$, using 1.0 $\mathrm{M} \mathrm{NaOH}$ solution. After the mixture was incubated at $80^{\circ} \mathrm{C}$ for $3 \mathrm{~d}$, the feedstock precoated with LDHs was washed with deionized water and dried at $105{ }^{\circ} \mathrm{C}$ for $24 \mathrm{~h}$. The production of BC-LDHs was performed in a horizontal electric tube furnace (New Separation Muffle AMF-N with Ceramic Electric Tubular Furnace ARF-30K, Asahi-Rika Co., Ltd., Aichi, Japan). Prior to commencing the experiment, the reactor was flushed with highly purified nitrogen gas for $30 \mathrm{~min}$ at a flow rate of $200 \mathrm{~mL} / \mathrm{min}$ to provide an oxygen-deficient atmosphere. Subsequently, RS-LDHs filled in a quartz boat were subjected to a heating zone at $475^{\circ} \mathrm{C}$ for $2 \mathrm{~h}$, which is a suitable condition for converting biomass into biochar and calcining LDHs simultaneously [2]. An inert atmosphere was established throughout the pyrolysis process until the BC-LDH samples had cooled to room temperature. When phosphate adsorption was achieved with as-prepared BC-LDHs in phosphate-containing water prepared from $\mathrm{KH}_{2} \mathrm{PO}_{4}$, the post-adsorption products were rinsed with deionized water and oven-dried at $105^{\circ} \mathrm{C}$ for $24 \mathrm{~h}$ to obtain P-BC-LDHs.

\subsection{Characterization of P-BC-LDHs}

Inductively coupled plasma atomic emission spectroscopy (ICP-AES, SPS3500, SII Nano Technology Inc., Tokyo, Japan) was performed to determine the nutrient and metal contents of the samples. Water holding capacity was analyzed following the method described by Bhadha et al. [15]. The moisture content was obtained by measuring the mass loss after drying the samples overnight at $105^{\circ} \mathrm{C}$. The cation exchange capacity (CEC) was measured via saturation with a sodium acetate solution with a $\mathrm{pH}$ value of 8.2. The $\mathrm{pH}$ and electrical conductivity (EC) were measured using a $\mathrm{pH}$ meter (D-51, Horiba, Ltd., Kyoto, Japan) and an EC meter (ES-14, Horiba, Ltd., Kyoto, Japan), respectively. These analyses were carried out following the methods outlined by the Food and Agricultural Organization of the United Nations [16].

\subsection{Seed Germination and Early Plant Growth Experiments}

The promotive effects of P-BC-LDHs on seed germination and early seedling growth were observed by comparing treatment groups with control groups (without P-BC-LDHs). The experimental design was a randomized block with four replicates for each treatment and the control group. Lettuce (Lactuca sativa L.) was chosen as the testing plant because of its short growth cycle and common consumption worldwide. Before planting, the surfaces 
of the lettuce seeds were sterilized with $0.1 \%$ sodium hypochlorite solution for 5 min to avoid bacterial contamination, and then washed with deionized water. Next, 50 disinfected seeds were placed on moistened filter paper (Whatman No. 1) and placed in Petri dishes containing $0.5,1.0,2.5$, and $5.0 \mathrm{~g}$ of P-BC-LDHs, which were denoted as T1, T2, T3, and $\mathrm{T} 4$, respectively. These dosages were selected on the basis of the recommended amounts of biochar provided by Solaiman et al. [17]. In their study, the potentially toxic effects of biochar on seed germination and early seedling growth were evaluated. The control groups were prepared using only deionized water. The Petri dishes were covered and incubated at $25^{\circ} \mathrm{C} \pm 0.5^{\circ} \mathrm{C}$ for $5 \mathrm{~d}$ under dark conditions. A seed was scored as germinated when the radicle protruded at least $1 \mathrm{~mm}$ [18]. After $5 \mathrm{~d}$ of incubation, various growth parameters, including germination percentage, seedling length, and fresh weight, were recorded for both the control and treated plants. The length of the seedling can be defined as the sum of the leaf, stem, and root lengths. The quantitative determination of changes in plant morphology was carried out using Image J 1.41 software (National Institute of Mental Health, Bethesda, MD, USA). The dry weight was calculated by maintaining seedlings at a temperature of $80^{\circ} \mathrm{C}$ for $72 \mathrm{~h}$, and the elemental contents of the biomass were recorded using ICP-AES.

To further determine the effects of different concentrations of P-BC-LDHs on plant growth during the initial period of development, additional experiments were conducted using four treatments $(0.5 \%, 1.0 \%, 2.5 \%$, and $5.0 \%(w / w))$, which were selected based on common use rates for biochar fertilization according to previous studies $[19,20]$. Each treatment was named T5, T6, T7, and T8, respectively. Sphagnum peat-based growing media (20 g) were thoroughly blended with each P-BC-LDH treatment and placed in plastic containers. Untreated substrates (without fertilization) served as the controls. Each lettuce seedling of a similar size germinated after $5 \mathrm{~d}$ was then planted in those containers and kept in a chamber at a temperature of $23{ }^{\circ} \mathrm{C} \pm 0.5^{\circ} \mathrm{C}$ and with a daily photoperiod of $18 \mathrm{~h}$ under LED light (two 7.5 watt tubes, Nikki Trading Corporation, Osaka, Japan). Plant growth parameters and their elemental compositions were recorded $21 \mathrm{~d}$ after transplanting. Shoot length was expressed as the base of lettuce to the tip of the tallest leaf, and root length referred to the base of lettuce to the longest root tip. The experiments were performed in four replicates, and the results were presented as an average.

\subsection{Nutrient Leaching Experiments}

The P-BC-LDHs were accompanied by aluminum and magnesium, which were used as metal cations in the synthesis of LDHs, and the excessive dissolution of these elements can be a detrimental constraint to plant growth, particularly aluminum, which is considered to be phytotoxic to the majority of plants. Therefore, following methods modified from previous studies [21,22], the cumulative release of both aluminum and magnesium, in addition to phosphorus as a function of time for the prepared fertilizer, was examined at room temperature $\left(23^{\circ} \mathrm{C} \pm 0.5^{\circ} \mathrm{C}\right)$. The experimental setup was constructed by placing a filter paper (Whatman No. 42) at the bottom of the columns to prevent particle loss during the leaching experiments. Growing substrates mixed with P-BC-LDHs at ratios of 0.5\%, $1.0 \%, 2.5 \%$, and $5.0 \%(w / w)$ were then packed in each column with an inner diameter of $3 \mathrm{~cm}$ and a length of $12 \mathrm{~cm}$. After settlement, deionized water was continuously pumped from the top of the columns at a rate of $100 \mathrm{~mL} /$ day using a peristaltic pump (MP-1000, Tokyo Rikakikai Co., Ltd., Tokyo, Japan), and the leachate solution collected at different time intervals was filtered through 1.0- $\mu \mathrm{m}$ PTFE membrane filters to analyze nutrient concentrations. Triplicate measurements were taken for the experiments, and the average values were calculated.

\subsection{Statistical Analysis}

A one-way analysis of variance (ANOVA) with a Tukey-Kramer post-hoc test was performed using Microsoft Excel to determine whether statistical differences existed between 
the treatments and control groups. Differences were considered significant at $p<0.05$. The mean and standard deviation were calculated for all data.

\section{Results and Discussions}

\subsection{Fertilizer Characterization}

The characteristics of the P-BC-LDHs prepared in this study are listed in Table 1 . The PBC-LDHs had a high initial $\mathrm{pH}$ of 9.02, and as such, the use of these materials in soil would exert a positive liming effect, which can remediate soil acidity and lead to improved soil fertility [23]. An understanding of the amount of soluble salts in P-BC-LDHs is important because its application to soil or growing media at high concentrations may adversely affect salt-sensitive plants [24]. Owing to a lack of available data corresponding to the EC values of biochar-based functional materials, the EC values of P-BC-LDHs $(1.36 \mathrm{dS} / \mathrm{m})$ were comparable to those of biochar samples, which were mostly grouped into 0.04 to $54.2 \mathrm{dS} / \mathrm{m}$ [24]. The moisture content and water-holding capacity were $2.20 \%$ and $65 \%$, respectively. It was expected that the high surface area and porosity of biochar in this composite were responsible for its high water retention, which was significantly higher than that of sandy soil after organic amendment through the addition of clay (4-13\%) [25]. The high water-holding capacity of the composite will enhance the efficiency of water use in agricultural production in terms of the water supply for plants. It was observed that P-BC-LDHs also had a high nutrient retention capacity, with a CEC of $23.1 \mathrm{cmol} / \mathrm{kg}$. This was because of the combined effect of specific surface area, porosity, and the chemical functional groups of biochar [26]. Moreover, the elemental analysis demonstrated that approximately $5 \mathrm{mg} / \mathrm{g}$ of phosphorus, $138 \mathrm{mg} / \mathrm{g}$ of magnesium, and $65 \mathrm{mg} / \mathrm{g}$ of aluminum were accommodated into the P-BC-LDHs. Phosphorus and magnesium have been widely acknowledged as essential macronutrients that are required in large amounts for plant growth and development.

Table 1. Basic physicochemical properties and heavy metal concentrations of P-BC-LDHs obtained from this study.

\begin{tabular}{|c|c|c|}
\hline \multicolumn{2}{|c|}{ Parameters } & Values \\
\hline \multicolumn{2}{|c|}{$\mathrm{pH}$} & $9.02 \pm 0.020$ \\
\hline \multicolumn{2}{|c|}{ Electrical conductivity $(\mathrm{EC})(\mathrm{dS} / \mathrm{m})$} & $1.36 \pm 0.016$ \\
\hline \multicolumn{2}{|c|}{ Moisture content (\%) } & $2.20 \pm 0.286$ \\
\hline \multicolumn{2}{|c|}{ Water holding capacity (\%) } & $65 \pm 0.000$ \\
\hline \multicolumn{2}{|c|}{ Cation exchange capacity (CEC) (cmol/kg) } & $23.1 \pm 1.274$ \\
\hline \multicolumn{2}{|c|}{ Phosphorus (mg/g) } & $4.67 \pm 0.055$ \\
\hline \multicolumn{2}{|c|}{ Magnesium (mg/g) } & $138 \pm 2.807$ \\
\hline \multicolumn{2}{|c|}{ Aluminum $(\mathrm{mg} / \mathrm{g})$} & $64.7 \pm 2.220$ \\
\hline Pollutants & Values & Maximum Acceptable Levels \\
\hline Cobalt (mg/g) & ND & 0.15 \\
\hline Nickle (mg/g) & ND & 0.18 \\
\hline Copper $(\mathrm{mg} / \mathrm{g})$ & $0.0325 \pm 0.005$ & - \\
\hline Zinc (mg/g) & $0.0519 \pm 0.003$ & 1.85 \\
\hline Cadmium (mg/g) & ND & 0.02 \\
\hline Molybdenum (mg/g) & ND & 0.02 \\
\hline Lead (mg/g) & ND & 0.50 \\
\hline
\end{tabular}

Data presented in the table are represented as the mean \pm standard deviation of the triplicate measurements. ND: not determined. 
Raw materials used in the manufacturing process of common commercial fertilizers are usually insufficiently purified, and this will lead to the inadvertent addition of heavy metals, such as cadmium, nickel, and lead to the environment and the transfer of these metals to the human food chain. The assessment of heavy metal contamination showed that no hazardous elements, including cobalt, nickel, cadmium, molybdenum, and lead, were present in these products. However, copper and zinc were detected, probably because biochar has inherent heavy metals within the structure derived from its source materials, which may be concentrated in ash fractions during pyrolysis [27]. The concentrations of these two elements were extremely low (less than $0.1 \mathrm{mg} / \mathrm{g}$ ) and below the Canadian standard adopted for heavy metals in fertilizer products [28], indicating that the application of $\mathrm{P}-\mathrm{BC}$-LDHs is not considered to have detrimental effects in terms of heavy metal pollution.

\subsection{Seed Germination}

Seed germination is one of the most crucial phases in the plant life cycle and is a determinant of crop productivity. Therefore, successful seed germination and early seedling growth characteristics can be early indicators for evaluating the usability of P-BC-LDHs in agronomic systems. As a first step towards understanding whether and how P-BC-LDHs can modulate the production of plants, the effects of P-BC-LDHs on the yield and quality of lettuce seeds cultivated at different dosages of these products were compared (Figure 1). On the first day of the experiments, it is likely that the stimulation of seedling emergence is observed in response to an increase in the concentration of P-BC-LDHs (Figure 1a). The seed germination percentages for T1, T2, T3, and T4 were 93\%, 94\%, 96\%, and 96\%, respectively, whereas that of the untreated seeds was $94 \%$. The final percentages of seedling establishment on the last day of germination for all treatment groups remained high, with a maximum germination rate of $99 \%$. However, there were no significant differences among lettuce seeds planted with and without P-BC-LDHs $(p>0.05)$.

Figure $1 b, c$ presents the growth characteristics of seedlings harvested after the experiments. Seedling lengths were significantly different between the control and treatment groups $(p<0.05)$. The greatest seedling length $(36.43 \mathrm{~mm})$ was found in the control plants, and that of the treated plants ranged from $18.41 \mathrm{~mm}$ to $24.52 \mathrm{~mm}$.

Similarly, fresh biomass was significantly affected by the application rate of P-BCLDHs. The total mass of seedlings for all cases of the addition of P-BC-LDHs decreased by approximately $20 \%$ to $54 \%$ compared to that of the non-treated seedlings. In contrast, the promotion of dry matter accumulation indicates that seedlings in better condition (0.044-0.051 g) were derived from P-BC-LDH treatments, which is comparable to the control group $(0.039 \mathrm{~g})$. The overall findings from the seed germination bioassay reveal that across all treatments, T3 showed the best potential for efficient seedling establishment, as well as the development of seedling lengths and biomass yields. However, the cultivation of seeds under non-treatment conditions allowed for the healthier growth of germinated seeds.

Given that the presence of soluble forms of aluminum in soil has long been recognized as the main deterrent restricting the growth of several agricultural crops, it is possible that the phytotoxic effect of aluminum would occur among seedlings exposed to P-BC-LDHs because this element was used for the synthesis of the composite. Aluminum did not interfere significantly with seed germination, but it impaired their morphological features, including seedling height and fresh biomass. This inhibition of plant growth has been broadly indicated as the primary response to aluminum toxicity, which is in agreement with other studies that detected a significant reduction in biomass, as well as the root and shoot length of many plants treated with varying levels of aluminum [29-31]. This negative feedback in plants was a consequence of aluminum penetration into plant tissues, which then promoted the rigidification of the cell walls and resulted in the prevention of root development. Furthermore, the suppression of root growth could ultimately cause the blockage of nutrient and water transport, leading to a decrease in biomass content and seedling length [32]. 


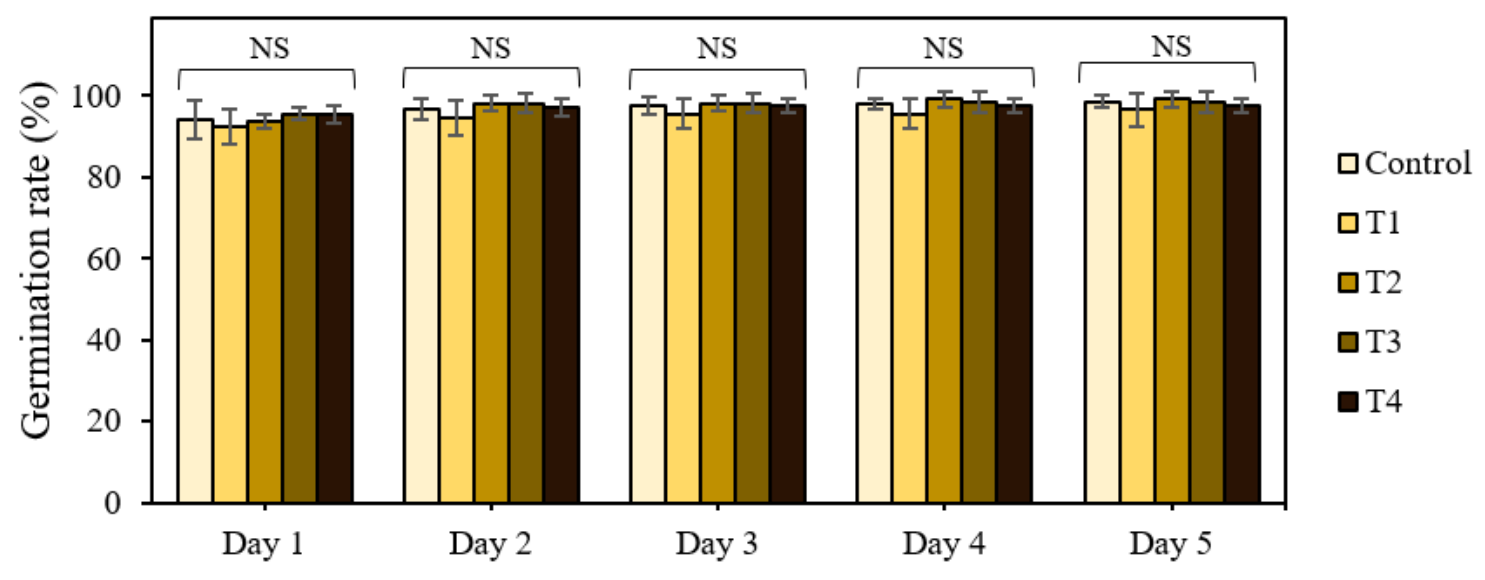

(a)

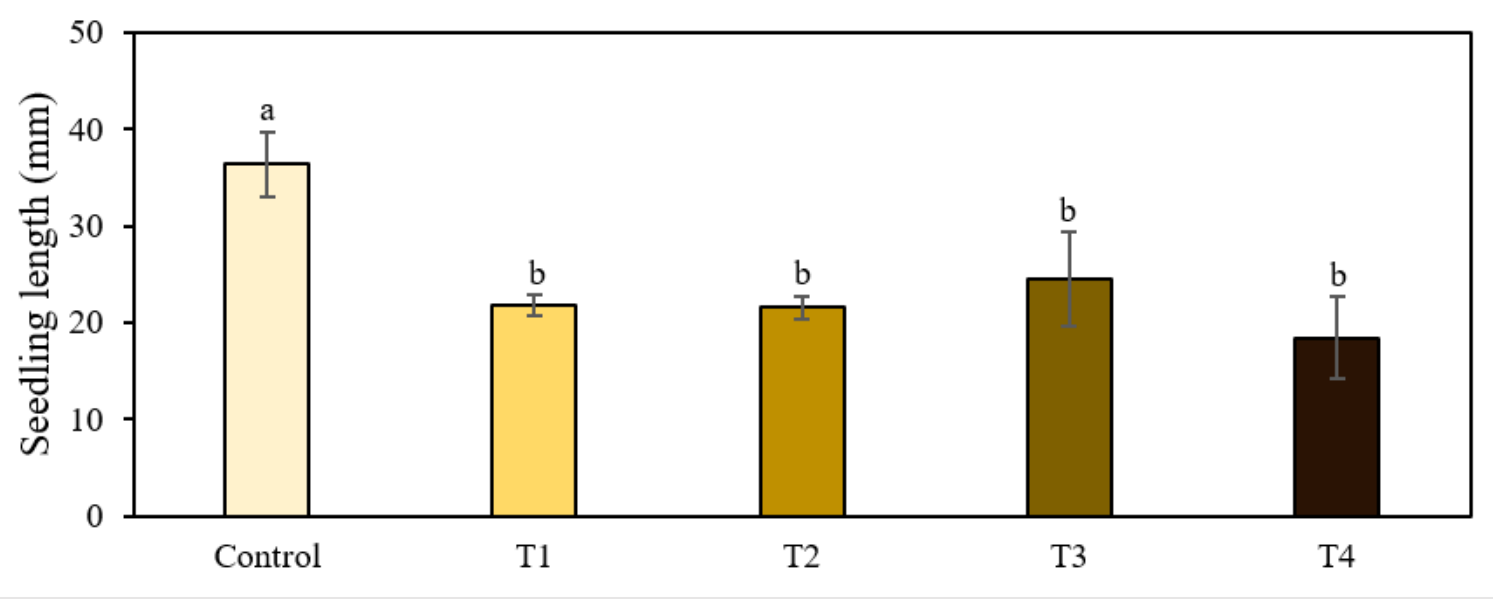

(b)

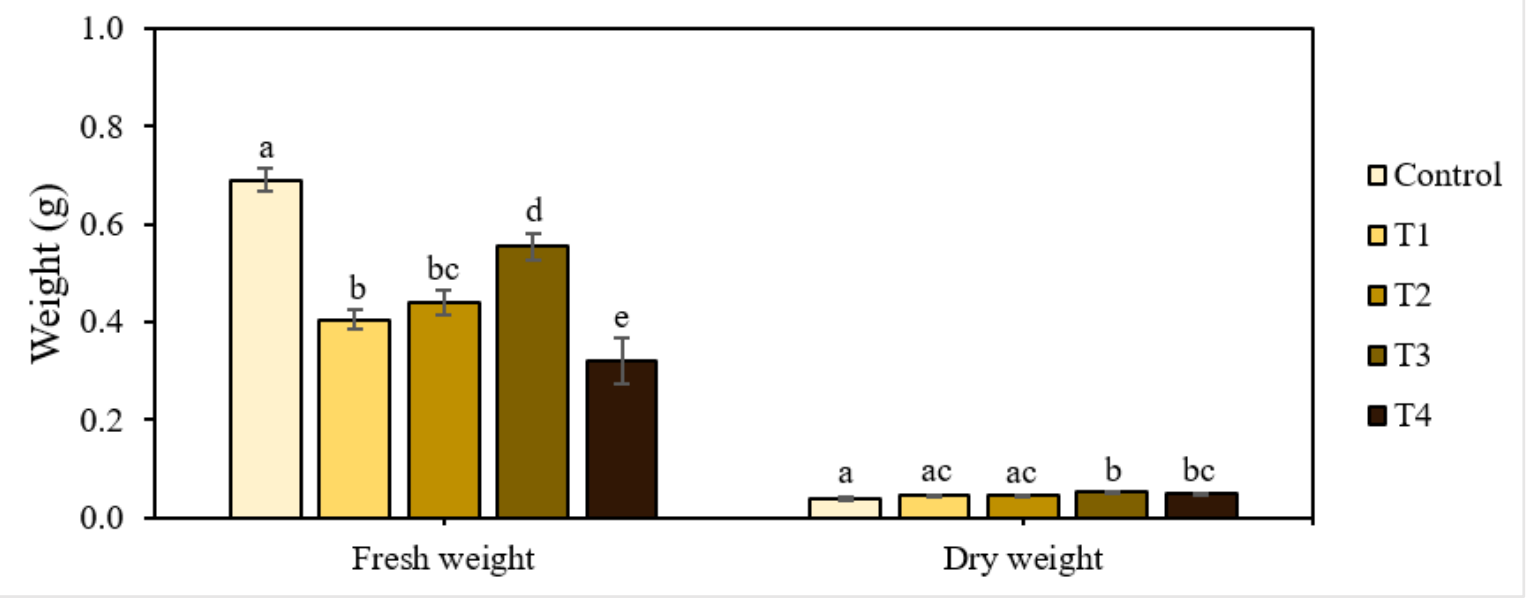

(c)

Figure 1. Effect of P-BC-LDHs applied at different rates on seed germination and growth parameters. (a) Germination percentage, (b) seedling length, and (c) fresh and dry weight. Same letters indicate that there are no statistically significant differences among groups. NS indicates no significance.

The elemental composition analysis also confirmed the accumulation of aluminum in dried seedlings with fertilization (Figure 2). There was a clear correlation between the 
increase in aluminum levels with the addition of P-BC-LDHs. Lettuce seeds imbued in $\mathrm{T} 1, \mathrm{~T} 2, \mathrm{~T} 3$, and $\mathrm{T} 4$ had average aluminum accumulation values of 1.10, 1.39, 2.36, and $2.81 \mathrm{mg} / \mathrm{g}$, respectively. In contrast, this metal was almost absent in the control lettuce. In addition, a dosage-dependent content of magnesium in seedlings was found, but a slight drop in phosphorus was verified in enhanced concentrations of P-BC-LDHs. It has been established that phosphorus deficiency is generally correlated with aluminum because of the formation of insoluble aluminum phosphate compounds, by which the absorption of such nutrients becomes ineffective [33]. In these experiments, we proposed that such undissolved complexes could be formed and progressively accumulate in the root tissues of lettuce seedlings, with increasing aluminum levels coinciding with the P-BC-LDH supply, inducing a decreased translocation of phosphorus to their stems and leaves. In addition, polycyclic aromatic hydrocarbons (PAHs), which are multi-ringed aromatic compounds, are formed during biochar production due to incomplete combustion [34,35]. These organic pollutants in P-BC-LDHs may be considered one of the factors inhibiting the growth of lettuce seedlings. It was reported that PAH-induced responses in several plants included the reduction of seed germination, hindered seedling development, and decreased root elongation due to the variable consequences of interference with cell wall modification and expansion, membrane permeability, and photosynthesis [36-39]. Therefore, to avoid any potentially toxic effects, the quantitative analyses of metal elements and PAHs, as well as pretreatment of P-BC-LDHs, should be performed prior to application for seed germination. A photograph of seed germination in response to different intakes of P-BC-LDHs on day five is shown in Figure 3a.

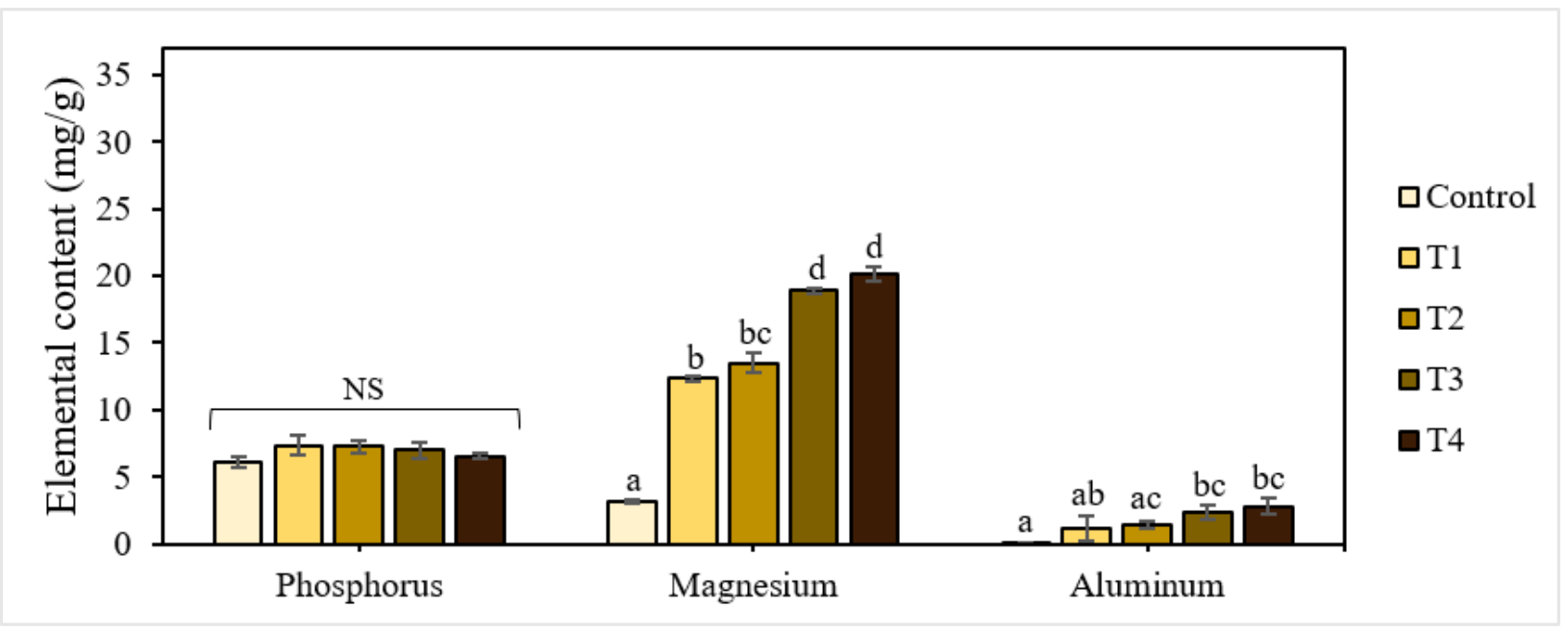

Figure 2. Elemental composition of seedlings under different application rates of P-BC-LDHs. Different letters indicate statistically significant differences. NS indicates no significance.

\subsection{Early Growth Stage}

In addition to evaluating the performance of various dosages of P-BC-LDHs on seed germination, fertilizer administration is also critical during the initial period of plant development in order to maintain adequate nutrient levels for crop nutrition. Furthermore, because nutrient requirements vary depending on the crop growth stage, such a relationship would be synergistic at a certain concentration range of P-BC-LDHs but may become antagonistic when its concentration is too high. In these contexts, the successive early-stage growth responses of lettuce in relation to the application of P-BC-LDHs were evaluated. In these experiments, lettuce was cultured in realistic growing systems in combination with various use rates of P-BC-LDHs. Multiple vegetative growth indices among individual treatments were compared. 


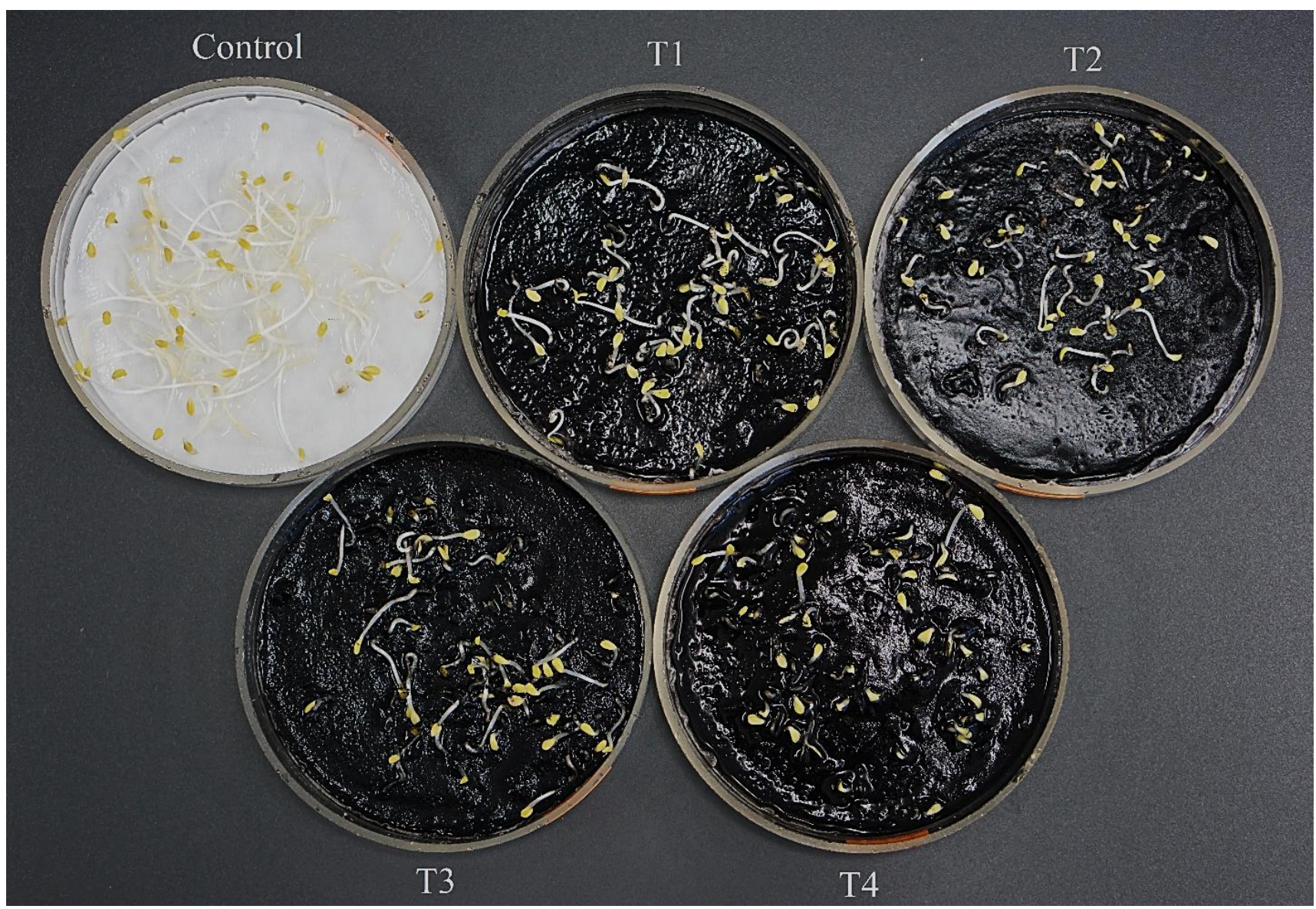

(a)

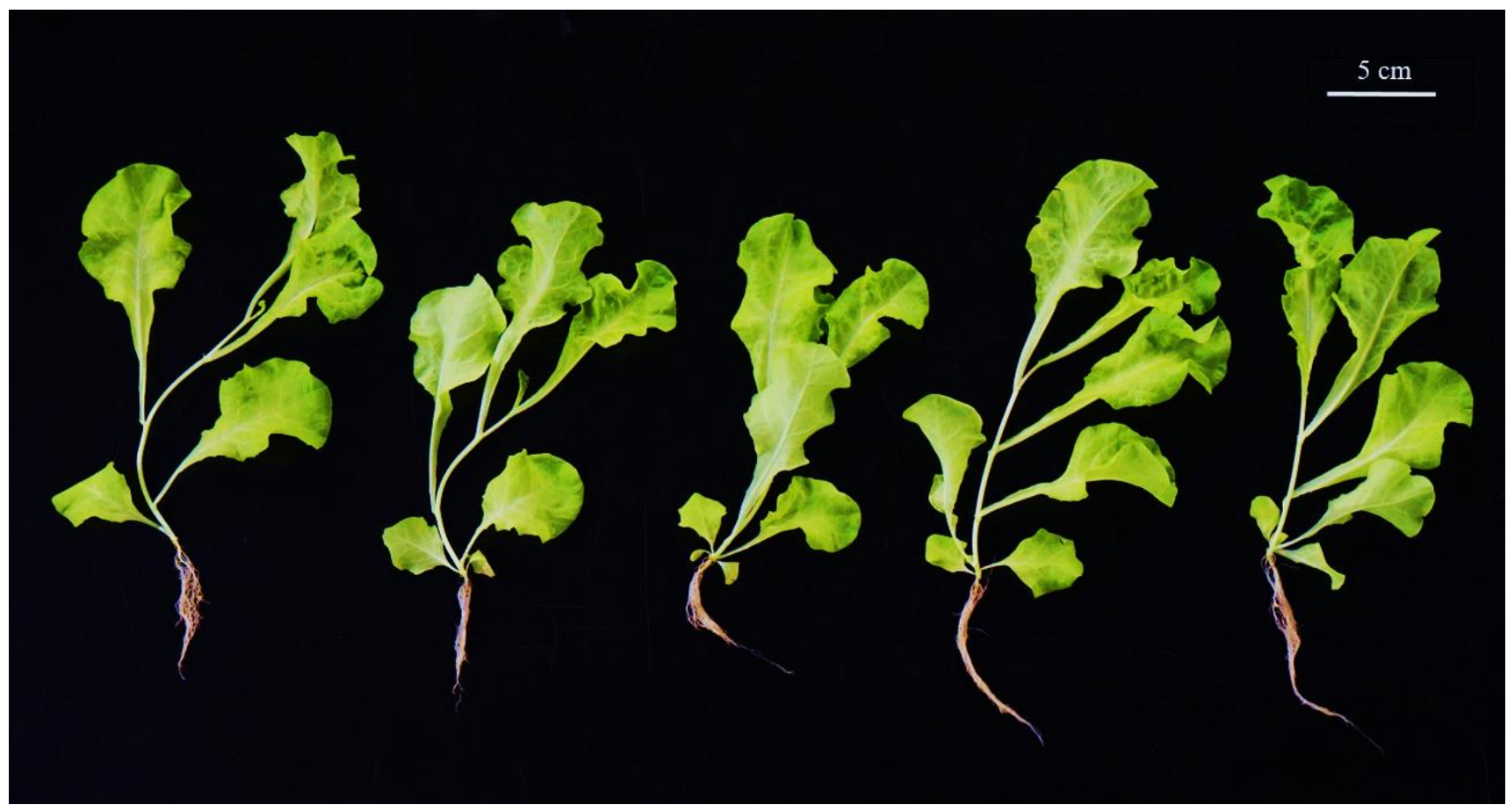

(b)

Figure 3. (a) Seeds germinated on day 5 under different concentrations of P-BC-LDHs. (b) Comparison of lettuce grown under control conditions and with different treatments of P-BC-LDHs. 
The shoot and root lengths of the 21-day-old lettuce plants are shown in Figure $4 \mathrm{a}$. The treatments with P-BC-LDHs positively affected these growth attributes, enabling a gradual increase in total plant height compared to the untreated control. Specifically, lettuce grown under mixtures with more P-BC-LDHs showed a superior shoot growth performance, which was larger by a factor of approximately 1.1 compared to those with less P-BCLDHs. Shoot height was lowest for plants from the untreated control group. However, there were no significant differences among lettuce planted with and without P-BC-LDHs $(p>0.05)$. Following a similar trend, the presence of P-BC-LDHs was also beneficial to root elongation. Under untreated control conditions, the poorest root improvement was observed at $69.45 \mathrm{~mm}$ in length. In contrast, when the growing medium was amended with P-BC-LDHs, they had longer roots, especially those from T7 and T8, of which a significant enhancement of up to $45 \%$ was attained $(p<0.05)$. For lettuce yield responses, all treatments acquired the ability to promote fresh biomass (Figure $4 \mathrm{~b}$ ). With fertilization, biomass production averaged from $2.035 \mathrm{~g}$ to $2.229 \mathrm{~g}$, which was higher than that of vegetables from the untreated control group (1.946 g). Moreover, a reduction of at least $10 \%$ in dry weight values was seen when P-BC-LDHs were not used. However, the application of these materials did not significantly affect either fresh weight or dry matter accumulation $(p>0.05)$. Although these favorable outcomes corresponded to a rise in P-BC-LDH dosages and the outstanding growth quality was more pronounced in plants from the last two highest composite intakes, there were no meaningful differences between samples from T7 and T8 $(p>0.05)$. In this study, $2.5 \%(w / w)$ of P-BC-LDH supply was sufficient for the advancement of lettuce traits.

The elemental analysis (Figure 4c) further highlights the effect of the dosing quantity of P-BC-LDHs on plant nutrient uptake. The assimilation of P-BC-LDHs in substrates resulted in an excellent phosphorus concentration within the plant tissues. In particular, a more significant influence on phosphorus uptake was observed in the treatments with higher dosages (T7 and T8), which increased by up to $21 \%$ and $27 \%$, respectively, compared to the other treatments and controls. Simultaneously, a larger amount of magnesium (by a factor of approximately 1.1) was also detected for all the treated lettuce. This suggests that the resultant fertilizer could provide this agricultural growing media with more available nutrients for plants, and therefore contribute to satisfactory vegetable growth that is superior to those grown without P-BC-LDHs. The changes in the aluminum level, which is a potentially toxic constituent for crop production and a consideration in this study, were extremely modest, with a statistically insignificant relationship between individual treated and control plants $(p>0.05)$. In general, aluminum is typically found as a mineral in the soil, and in strongly acidic soil, especially at $\mathrm{pH}$ values lower than 4.3 , it will severely impede the physiological and biochemical processes of plants [40]. Consequently, their productivity will be impeded due to its excessive solubilization and the enhanced presence of trivalent aluminum $\left(\mathrm{Al}^{3+}\right)$, which is known to be the most toxic form $[40,41]$. Due to the alkalinity of P-BC-LDHs (Table 1), the application of P-BC-LDHs could compensate for the acidic growing media used, which greatly assisted the amelioration of aluminum phytotoxicity. In this study, the $\mathrm{pH}$ measurements of each substrate were performed after 21 days. The effectiveness of these materials in improving the $\mathrm{pH}$ of all growing media was demonstrated, with values ranging from 4.7 to 5.2, which was comparable to those without amendment (4.4). Furthermore, it has been proposed that young seedlings are more prone to aluminum stress than older plants [42]. Therefore, the lettuce observed in the present study did not demonstrate any signs of toxicity even at high applied concentrations of P-BC-LDHs, which was inconsistent with their interaction with seed germination. 


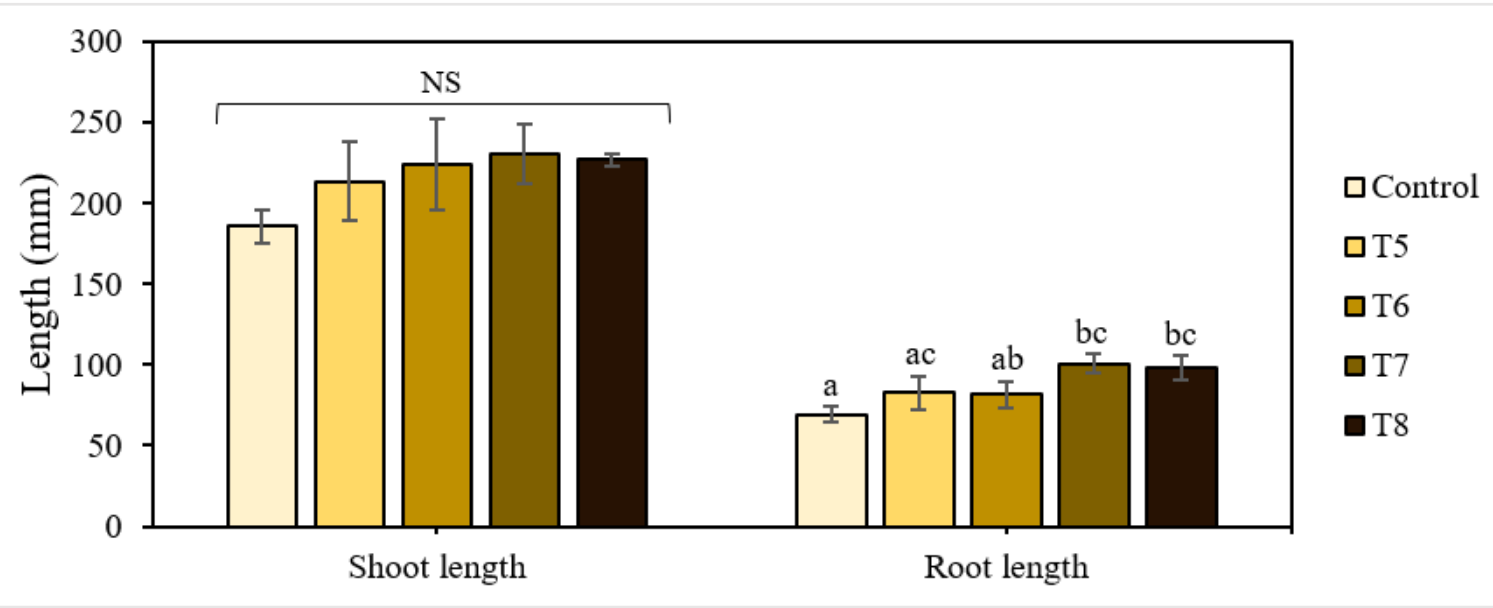

(a)

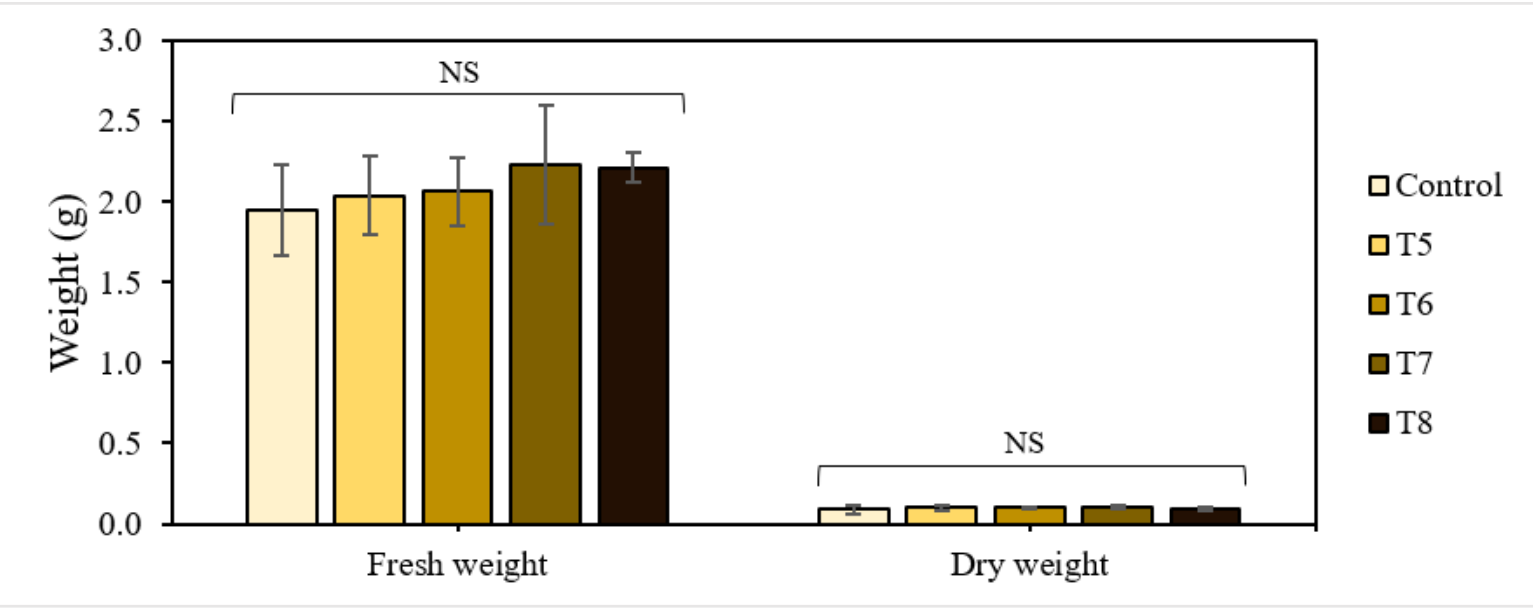

(b)

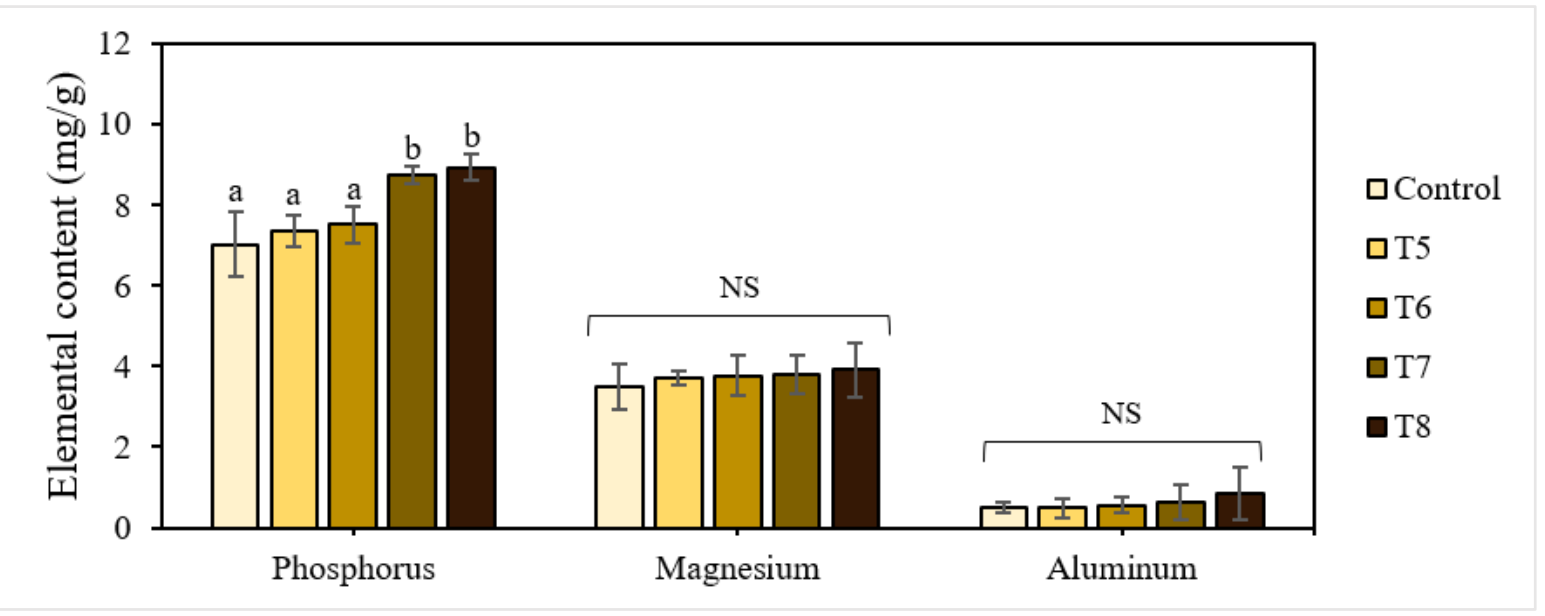

(c)

Figure 4. Effect of P-BC-LDHs at different dosages on growth parameters and the elemental composition of lettuce from early plant growth experiments. (a) Shoot and root length, (b) fresh and dry weight, and (c) elemental analysis. Different letters indicate statistically significant differences. NS indicates no significance.

Notably, in addition to being a good source of nutrients, its excellent characteristics, including high $\mathrm{pH}$, water retention, and CEC (Table 1) values, could partly account for the 
observed growth stimulation in lettuce. There were correlated consequences of increasing $\mathrm{pH}$ in the P-BC-LDH-treated growing media, where microorganism activity and nutrient availability were consecutively promoted in addition to aluminum tolerance, and therefore were beneficial to plant growth $[43,44]$. The biochar used in this study exhibited well developed porosity and a large surface area, and as such, there were many advantages in the addition of P-BC-LDHs in terms of the alteration of physical properties of the substrate, such as water storage capacity, penetration resistance, and bulk density. This, in turn, encouraged water and nutrient retention and minimized nutrient leaching, which indirectly complemented lettuce development $[45,46]$. In addition, it has been previously asserted that the high CEC of biochar could be another reason for improving phosphorus bioavailability and uptake [47]. Consequently, it is conceivable that the application of this spent adsorbent to agricultural growing media is highly successful in facilitating horticultural plant conditions when attempting to recycle it as a fertilizer. The recommended application amount of P-BC-LDHs is $2.5 \%(w / w)$. The differences between treatment and control lettuce crops are illustrated in Figure $3 b$.

\subsection{Release of Nutrients}

Some studies have hypothesized that LDHs could delay the discharge of nutrients because of the mechanism of the anion exchange reaction taking place within its structure, and LDHs could therefore be targeted as a slow-release fertilizer. Consequently, the feasibility of P-BC-LDHs for controlled nutrient release for agricultural uses was also investigated. In the present experiments, for the first time, the release characteristics of magnesium and aluminum in real substrate systems were examined, in addition to those of phosphorus because current studies regarding biochar-based LDH composites have primarily focused on phosphorus dissolution under water conditions.

The actual cumulative release profiles in the substrate cultures of these elements (Figure 5) suggest that a progressive loss of nutrients is linked to increased sample dosages, except for phosphorus release tests, wherein the highest P-BC-LDHs applied did not result in extensive dissolution. However, a preferable sustained release behavior was obtained from all supplemented growing media. The sum of the phosphorus content on the first day (Figure 5a) for columns amended with $0.5 \%, 1.0 \%, 2.5 \%$, and $5.0 \%(w / w)$ was 0.015 , $0.019,0.021$, and $0.028 \mathrm{mg}$, respectively, indicating that all treatments accommodated approximately $0.8 \%$ of the total loaded phosphorus. This finding, which meets the criteria of no more than $15 \%$ of released nutrients within $24 \mathrm{~h}$, indicates good compliance with the standard of slow-release fertilizers according to the Committee of European Normalization [48]. Phosphorus leaching gradually occurred over time and at the end of the study, the cumulative release was $0.087,0.349,0.389$, and $0.204 \mathrm{mg}$ in $0.5 \%, 1.0 \%, 2.5 \%$, and $5.0 \%$ $(w / w)$ treatments, respectively.

The magnesium solubilizing patterns for every column exceeded that of phosphorus during the entire leaching experiment, particularly in the substrate amended with the maximum P-BC-LDH level (Figure $5 \mathrm{~b}$ ). The overall $\mathrm{Mg}$ losses from $0.5 \%, 1.0 \%, 2.5 \%$, and $5.0 \%(w / w)$ were $0.196,1.009,0.896$, and $3.875 \mathrm{mg}$, respectively, which is at least two times higher than that of phosphorus. The changes in the aluminum concentrations in the leachates collected are shown in Figure 5c. The changing tendency of released aluminum showed certain differences, for which P-BC-LDHs displayed significantly slower release behavior compared to both phosphorus and magnesium. The total amounts of aluminum from the leachate samples under applications of $0.5 \%, 1.0 \%, 2.5 \%$, and $5.0 \%(w / w)$ on the last day reached $0.078,0.090,0.127$, and $0.112 \mathrm{mg}$, respectively. Moreover, the ease of dissolution for these three nutrients was detected for zero-treatment columns, and their release profiles remained almost unchanged over the observed range of the experiments because of insufficient nutrients. 


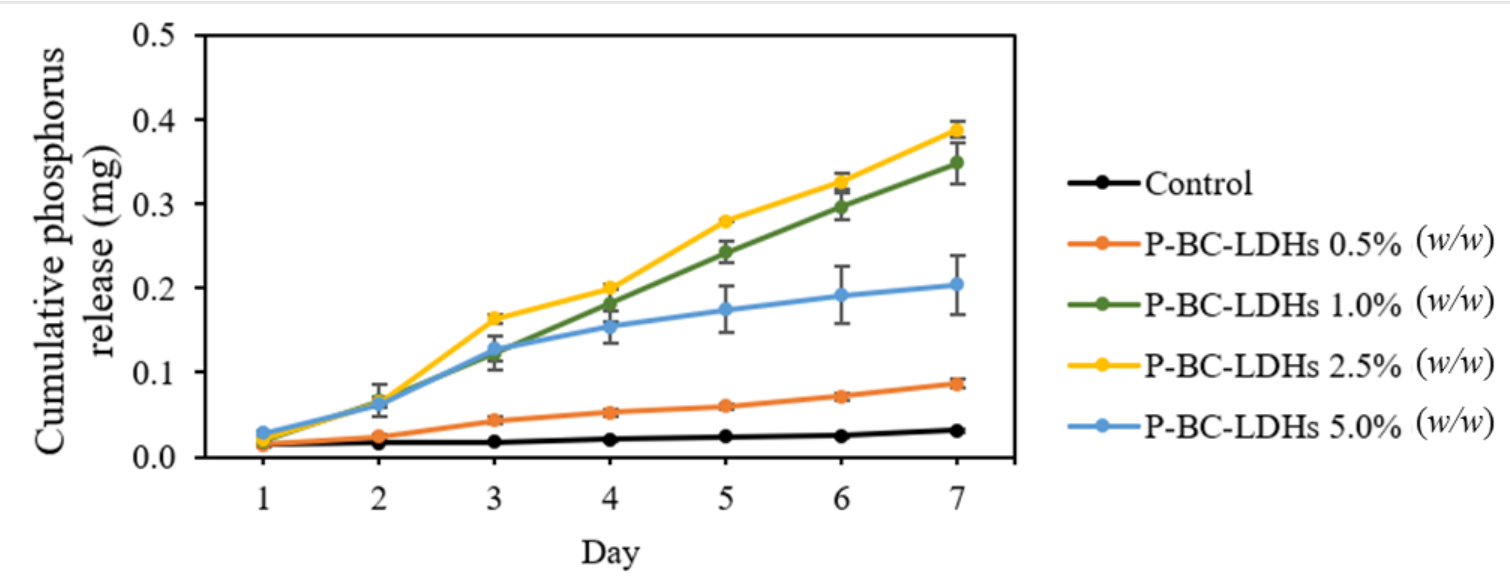

(a)

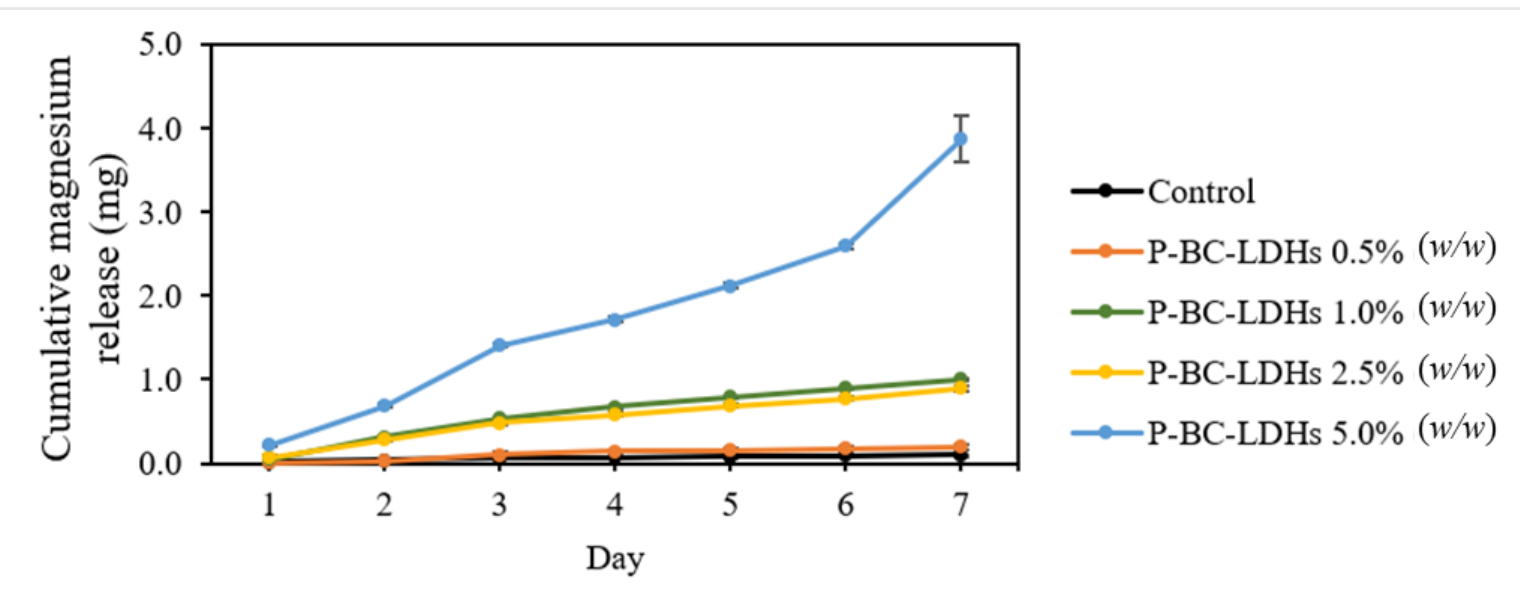

(b)

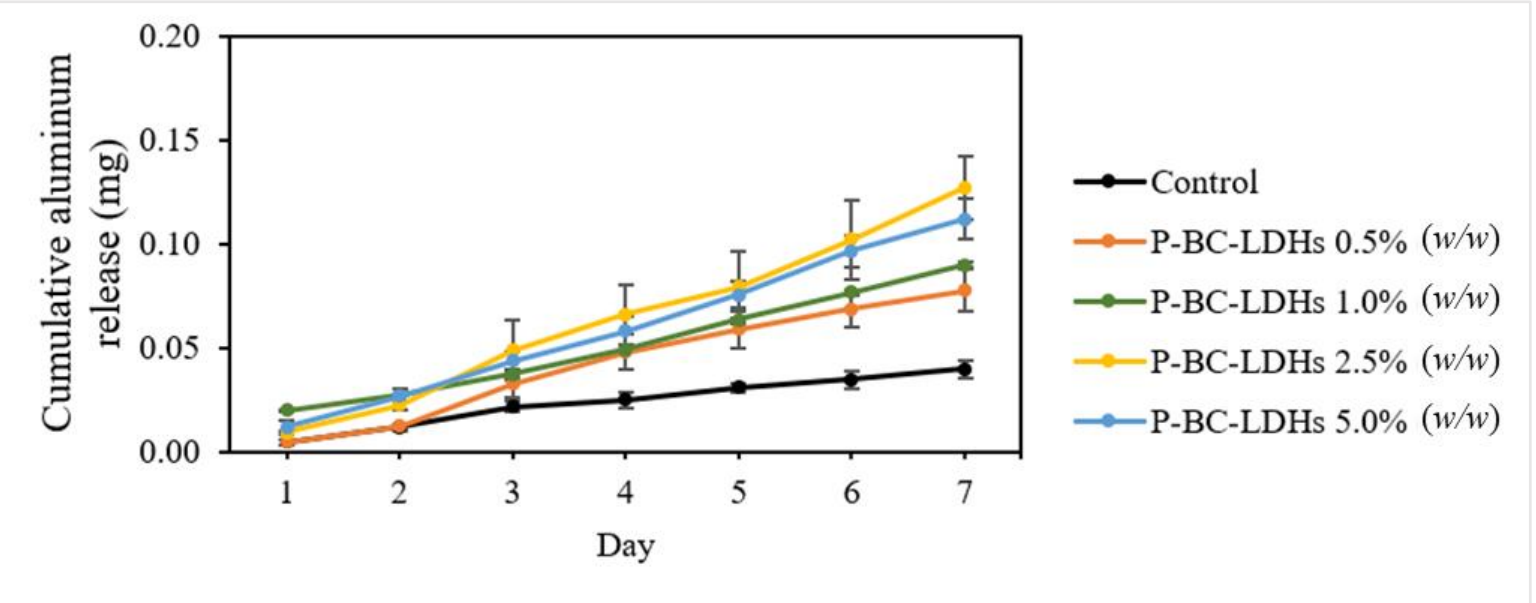

(c)

Figure 5. Cumulative nutrient release patterns as a function of time for different incorporations of P-BC-LDHs. (a) Phosphorus, (b) magnesium, and (c) aluminum.

The reason for this small phosphorus release was probably a phosphorus fixation reaction, whereby the surface functional groups, including carboxyl and hydroxyl enriched in partially carbonized biochar, could utilize bridged cations $\left(\mathrm{Al}^{3+}\right.$ and $\left.\mathrm{Mg}^{2+}\right)$ to form 
stable six-membered ring complexes with phosphate [49]. It is also estimated that the $\mathrm{pH}$ of growing substrates is an important factor controlling phosphorus release from these materials because phosphorus stabilization will take place upon increased $\mathrm{pH}$, resulting in reduced phosphorus leaching. Another possible explanation is that under such high-pH conditions, the substrate cultures are rich in basic salts, such as $\mathrm{K}^{+}, \mathrm{Na}^{+}$, and $\mathrm{Ca}^{2+}$, and as such, phosphorus retention is dominated by the poor mobility of formed phosphate minerals induced by strong reactivity with those anions [50-52]. At the same time, the reduced acidity in the growing media after the application of P-BC-LDHs was capable of reducing the solubility of aluminum. It has been reported that enriching soil with a sustainable silicon source, such as rice straw biochar, containing approximately $10-20 \%$ silicon, can help to lower the aluminum concentration and enhance soil health and plant growth [53]. Therefore, it can be assumed that the abundant silicon within the rice straw biochar structure located in this composite would combine with the aluminum in LDHs, or even in substrate cultures, to form hydroxy aluminosilicate complexes and reduce the potential leachable aluminum [42]. The mechanisms of the profound magnesium release from the prepared composite are explained as follows: generally, the highly mobile nature of magnesium makes it susceptible to less strong binding to soil or growing media charges, which can be ascribed to its larger hydrated radius than that of other available cations, such as calcium, potassium, and sodium [54]. Furthermore, magnesium ions, which are present in the LDH structure, would be replaced by other exchanging positively charged ions in the substrate solution, particularly by calcium, which has the same valence as magnesium and is also abundant in alkaline substrates [55].

The substantial dependence on phosphorus as an indispensable ingredient of fertilizers, which has developed in agricultural production in response to increased food production, has led to an imminent depletion of phosphate rock reserves, which are the primary sources of phosphorus for agriculture. Furthermore, the current application of conventional phosphate fertilizers is repeatedly interrupted by runoff and leaching because of its high solubility. This means that the development of efficient phosphate fertilization practices has become increasingly important. Not only were P-BC-LDHs shown to have phosphate removal ability, but they also demonstrated positive effects on horticultural plant cultivation systems, in which both the agricultural product quality and availability of nutrients were improved. To confirm their practical application, more studies are necessary to further examine their longer release behaviors under natural field conditions.

\section{Conclusions}

The removal and recovery of phosphate has attracted growing interest because of the two issues of aquatic eutrophication and global phosphate rock scarcity. Here, biochar functionalized with layered double hydroxides (BC-LDHs) was developed for the previous abatement of excess phosphate in water bodies, and post-adsorption BC-LDHs (P-BCLDHs) were sequentially assessed for their application potential as a phosphate fertilizer. The lettuce seed germination treatments included four levels of P-BC-LDHs $(0.5,1.0,2.5$, and $5.0 \mathrm{~g}$ ). The effects of P-BC-LDHs on seedling emergence during the first $24 \mathrm{~h}$ were more pronounced with increasing P-BC-LDHs. Treated and non-treated samples did not significantly differ on the last day of germination $(p>0.05)$, in contrast with the subsequent experiments, in which lettuce crops were grown in growing media with $0.5 \%, 1.0 \%, 2.5 \%$, and $5.0 \%(w / w)$ of P-BC-LDHs. The high input of P-BC-LDHs led to the best nutrient accumulation levels within plant tissues and the best growth features, particularly in terms of the root characteristics, where the length was significantly improved by up to $45 \%$ in the $2.5 \%(w / w)$ treatment compared with that of the control $(p<0.05)$. The fact that P-BC-LDHs improved nutrition and created desirable conditions for lettuce growth could explain these phenomena. A comparison of the leaching behaviors among phosphorus, magnesium, and aluminum suggested that P-BC-LDHs achieved a slower release of phosphorus, which could extend the time of nutrient availability for plant uptake. The transformation of phosphate-loaded adsorbents into fertilizers offers an appealing alternative method of 
resource recycling from waste streams, which promotes new sustainable and economic strategies for improving the management of phosphate utilization. Aluminum and PAHs are likely potential contaminants found in P-BC-LDHs and may pose toxicological risks to plants and soil microbial activity. Hence, future studies directed toward the precise assessment of the impacts of P-BC-LDHs on the long-term persistence or bioavailability of these contaminants in the environment will provide valuable information and provide insights into the application of P-BC-LDHs as fertilizers.

Supplementary Materials: The following are available online at https:/ /www.mdpi.com/article/10 .3390/app11146489/s1.

Author Contributions: Conceptualization, J.B.; methodology, J.B.; investigation, J.B.; writingoriginal draft preparation, J.B.; writing-review and editing, T.I.; supervision, T.I. Both authors have read and agreed to the published version of the manuscript.

Funding: This research received no external funding.

Institutional Review Board Statement: Not applicable.

Informed Consent Statement: Not applicable.

Data Availability Statement: Not applicable.

Acknowledgments: The authors thank Takaya Higuchi for kindly providing a horizontal electric tube furnace for the biochar preparation used in this study. The authors also thank Editage (www.editage.com) for English language editing.

Conflicts of Interest: The authors declare no conflict of interest.

\section{References}

1. Zhang, L.; Liu, J.; Guo, X. Investigation on mechanism of phosphate removal on carbonized sludge adsorbent. J. Environ. Sci. (China) 2018, 64, 335-344. [CrossRef]

2. Buates, J.; Imai, T. Biochar functionalization with layered double hydroxides composites: Preparation, characterization, and application for effective phosphate removal. J. Water Process Eng. 2020, 37, 101508. [CrossRef]

3. Gao, L.; Wang, R.; Shen, G.; Zhang, J.; Meng, G.; Zhang, J. Effects of biochar on nutrients and the microbial community structure of tobacco-planting soils. J. Soil Sci. Plant Nutr. 2017, 17, 884-896. [CrossRef]

4. Man, Y.; Wang, B.; Wang, J.; Slaný, M.; Yan, H.; Li, P.; El-Naggar, A.; Shaheen, S.M.; Rinklebe, J.; Feng, X. Use of biochar to reduce mercury accumulation in Oryza sativa L: A trial for sustainable management of historically polluted farmlands. Environ. Int. 2021, 153. [CrossRef] [PubMed]

5. Adhikari, S.; Gascó, G.; Méndez, A.; Surapaneni, A.; Jegatheesan, V.; Shah, K.; Paz-Ferreiro, J. Influence of pyrolysis parameters on phosphorus fractions of biosolids derived biochar. Sci. Total Environ. 2019, 695, 133846. [CrossRef] [PubMed]

6. Ding, Y.; Liu, Y.; Liu, S.; Li, Z.; Tan, X.; Huang, X.; Zeng, G.; Zhou, L.; Zheng, B. Biochar to improve soil fertility. A review. Agron. Sustain. Dev. 2016, 36. [CrossRef]

7. Rawat, J.; Saxena, J.; Sanwal, P. Biochar: A sustainable approach for improving plant growth and soil properties. In Biochar-An Imperative Amendment for Soil and the Environment; 2019; pp. 1-17. [CrossRef]

8. Hameeda, G.S.; Bano, G.; Manzoor, M.; Chandio, T.A.; Awan, A.A. Biochar and manure influences tomato fruit yield, heavy metal accumulation and concentration of soil nutrients under wastewater irrigation in arid climatic conditions. Cogent Food Agric. 2019, 5, 1-15. [CrossRef]

9. William, K.; Qureshi, R.A. Evaluation of biochar as fertilizer for the qrowth of some seasonal vegetables. J. Bioresour. Manag. 2015, 2. [CrossRef]

10. Kameda, T.; Yoshiok, T. Hybrid inorganic/organic composites of layered double hydroxides intercalated with organic acid anions for the uptake of hazardous substances from aqueous solution. Met. Ceram. Polym. Compos. Var. Uses 2011.

11. Zhou, L.; Slaný, M.; Bai, B.; Du, W.; Qu, C.; Zhang, J.; Tang, Y. Enhanced removal of sulfonated lignite from oil wastewater with multidimensional MgAl-LDH nanoparticles. Nanomaterials 2021, 11, 861. [CrossRef]

12. Benício, L.P.F.; Silva, R.A.; Lopes, J.A.; Eulálio, D.; dos Santos, R.M.M.; de Aquino, L.A.; Vergütz, L.; Novais, R.F.; da Costa, L.M.; Pinto, F.G.; et al. Layered double hydroxides: Nanomaterials for applications in agriculture. Rev. Bras. Cienc. Do Solo 2015, 39, 1-13. [CrossRef]

13. Touloupakis, E.; Margelou, A.; Ghanotakis, D.F. Intercalation of the herbicide atrazine in layered double hydroxides for controlledrelease applications. Pest Manag. Sci. 2011, 67, 837-841. [CrossRef]

14. Cardoso, L.P.; Celis, R.; Cornejo, J.; Valim, J.B. Layered double hydroxides as supports for the slow release of acid herbicides. J. Agric. Food Chem. 2006, 54, 5968-5975. [CrossRef] 
15. Bhadha, J.H.; Capasso, J.M.; Khatiwada, R.; Swanson, S. Raising soil organic matter content to improve water holding capacity. Uf/Ifas 2017, 1-5. [CrossRef]

16. Food and Agricultural Organization of the United Nations. Procedures for Soil Analysis; International Soil Reference and Information Center: Wageningen, The Netherlands, 2002.

17. Solaiman, Z.M.; Murphy, D.V.; Abbott, L.K. Biochars influence seed germination and early growth of seedlings. Plant Soil 2012, 353, 273-287. [CrossRef]

18. Pauzaite, G.; Malakauskiene, A.; Nauciene, Z.; Zukiene, R.; Filatova, I.; Lyushkevich, V.; Azarko, I.; Mildaziene, V. Changes in Norway spruce germination and growth induced by pre-sowing seed treatment with cold plasma and electromagnetic field: Short-term versus long-term effects. Plasma Process. Polym. 2018, 15. [CrossRef]

19. Nguyen, T.T.N.; Xu, C.Y.; Tahmasbian, I.; Che, R.; Xu, Z.; Zhou, X.; Wallace, H.M.; Bai, S.H. Effects of biochar on soil available inorganic nitrogen: A review and meta-analysis. Geoderma 2017, 288, 79-96. [CrossRef]

20. Mukherjee, A.; Lal, R. The biochar dilemma. Soil Res. 2014, 52, 217-230. [CrossRef]

21. Duan, X.Y.; Cao, Y.; Liu, T.Z.; Li, L.; Wang, B.; Wang, X.D. Nutrient stability and sorption of sewage sludge biochar prepared from co-pyrolysis of sewage sludge and stalks/mineral materials. Environ. Pollut. Bioavailab. 2020, 32, 12-18. [CrossRef]

22. Ye, H.M.; Li, H.F.; Wang, C.S.; Yang, J.; Huang, G.; Meng, X.; Zhou, Q. Degradable polyester/urea inclusion complex applied as a facile and environment-friendly strategy for slow-release fertilizer: Performance and mechanism. Chem. Eng. J. 2020, 381, 122704. [CrossRef]

23. Shi, R.Y.; Hong, Z.N.; Li, J.Y.; Jiang, J.; Baquy, M.A.; Xu, R.K.; Qian, W. Mechanisms for Increasing the pH Buffering Capacity of an Acidic Ultisol by Crop Residue-Derived Biochars. J. Agric. Food Chem. 2017, 65, 8111-8119. [CrossRef]

24. Singh, B.; Dolk, M.M.; Shen, Q.; Camps-Arbestain, M. Biochar pH, electrical conductivity and liming potential. Biochar A Guid. Anal. Methods 2017, 23-38.

25. Tahir, S.; Marschner, P. Clay addition to sandy soil-Effect of clay concentration and ped size on microbial biomass and nutrient dynamics after addition of low C/N ratio residue. J. Soil Sci. Plant Nutr. 2016, 16, 864-875. [CrossRef]

26. Masís-Meléndez, F.; Segura-Chavarría, D.; García-González, C.A.; Quesada-Kimsey, J.; Villagra-Mendoza, K. Variability of physical and chemical properties of TLUD stove derived biochars. Appl. Sci. 2020, 10, 507. [CrossRef]

27. Lehmann, J.; Joseph, S. Biochar for Environmental Management: Science, Technology and Implementation; Routledge: Oxford, UK, 2015. [CrossRef]

28. Ukpabi, C.F.; Akubugwo, E.I.; Agbafor, K.N.; Lebe, N.A.; Nwaulari, N.J.; Nneka, E.D. Appraisal of heavy metal contents in commercial inorganic fertilizers blended and marketed in nigeria. Am. J. Chem. 2012, 2, 228-233. [CrossRef]

29. Nursyamsi, D.; Osaki, M.; Tadano, T. Effect of aluminum on plant growth, phosphorus and calcium uptake of tropical rice (Oryza sativa), maize (Zea mays), and soybean (Glycine max). Indones. J. Agric. Sci. 2000, 1, 51-62. [CrossRef]

30. Malik, B.; Pirzadah, T.B.; Tahir, I.; Hakeem, K.R.; Rather, I.A.; Sabir, J.S.M.; Rehman, R.U. Lead and aluminium-induced oxidative stress and alteration in the activities of antioxidant enzymes in chicory plants. Sci. Hortic. (Amst.) 2020, 109847. [CrossRef]

31. Tammam, A.A.; Khalil, S.M.; Hafez, E.E.; M. Elnagar, A. Impacts of aluminum on growth and biochemical process of wheat plants under boron treatments. Curr. Agric. Res. J. 2018, 6, 300-319. [CrossRef]

32. Osman, H.E.; Al-Jabri, M.; El-Ghareeb, D.K.; Al-Maroai, Y.A. Impact of aluminum and zinc oxides on morphological characters, germination, metals accumulation and DNA in fenugreek (Trigonella foenum-graecum). J. Saudi Soc. Agric. Sci. 2020. [CrossRef]

33. Dixon, M.; Simonne, E.; Obreza, T.; Liu, G. Crop response to low phosphorus bioavailability with a focus on tomato. Agronomy 2020, 10, 617. [CrossRef]

34. Intani, K.; Latif, S.; Islam, M.S.; Müller, J. Phytotoxicity of corncob biochar before and after heat treatment and washing. Sustainability 2018, 11, 30. [CrossRef]

35. Wang, C.; Wang, Y.; Herath, H.M.S.K. Polycyclic aromatic hydrocarbons (PAHs) in biochar-Their formation, occurrence and analysis: A review. Org. Geochem. 2017, 114, 1-11. [CrossRef]

36. Maliszewska-kordybach, B. Seed germination and root growth of selected plants in PAH contaminated soil. Fresenius Environ. Bull. 2014, 12, 946-949.

37. Al-Wabel, M.I.; Rafique, M.I.; Ahmad, M.; Ahmad, M.; Hussain, A.; Usman, A.R.A. Pyrolytic and hydrothermal carbonization of date palm leaflets: Characteristics and ecotoxicological effects on seed germination of lettuce. Saudi J. Biol. Sci. 2019, 26, 665-672. [CrossRef]

38. Nair, A.; Carpenter, B. Biochar rate and transplant tray cell number have implications on pepper growth during transplant production. Horttechnology 2016, 26, 713-719. [CrossRef]

39. Jajoo, A.; Mekala, N.R.; Tomar, R.S.; Grieco, M.; Tikkanen, M.; Aro, E.M. Inhibitory effects of polycyclic aromatic hydrocarbons (PAHs) on photosynthetic performance are not related to their aromaticity. J. Photochem. Photobiol. B Biol. 2014, 137, 151-155. [CrossRef] [PubMed]

40. Bojorquez-Quintal, E.; Escalante-Magaña, C.; Echevarría-Machado, I.; Martínez-Estévez, M. Aluminum, a friend or foe of higher plants in acid soils. Front. Plant Sci. 2017, 8, 1-18. [CrossRef] [PubMed]

41. Merino-Gergichevich, C.; Alberdi, M.; Ivanov, A.G.; Reyes-Díaz, M. $\mathrm{Al}^{3+}-\mathrm{Ca}^{2+}$ interaction in plants growing in acid soils: Al-phytotoxicity response to calcareous amendments. J. Soil Sci. Plant Nutr. 2010, 10, 217-243.

42. Neenu, S.; Karthika, K.S. Aluminium toxicity in soil and plants. ICAR 2019, 2, 15-19. 
43. Gentili, R.; Ambrosini, R.; Montagnani, C.; Caronni, S.; Citterio, S. Effect of soil pH on the growth, reproductive investment and pollen allergenicity of Ambrosia artemisiifolia L. Front. Plant Sci. 2018, 9, 1-12. [CrossRef]

44. de Figueiredo, C.C.; Reis, A.D.; de Araujo, A.S.; Blum, L.E.; Shah, K.; Paz-Ferreiro, J. Assessing the potential of sewage sludgederived biochar as a novel phosphorus fertilizer: Influence of extractant solutions and pyrolysis temperatures. Waste Manag. 2021, 124, 144-153. [CrossRef] [PubMed]

45. Liang, J.F.; An, J.; Gao, J.Q.; Zhang, X.Y.; Song, M.H.; Yu, F.H. Interactive effects of biochar and AMF on plant growth and greenhouse gas emissions from wetland microcosms. Geoderma 2019, 346, 11-17. [CrossRef]

46. Kerkeni, L.; Ruano, P.; Delgado, L.L.; Picco, S.; Villegas, L.; Tonelli, F.; Merlo, M.; Rigau, J.; Diaz, D.; Masuelli, M. Biochar and soil physical health. Intech 2016.

47. Chen, H.; Yang, X.; Wang, H.; Sarkar, B.; Shaheen, S.M.; Gielen, G.; Bolan, N.; Guo, J.; Che, L.; Sun, H.; et al. Animal carcass- and wood-derived biochars improved nutrient bioavailability, enzyme activity, and plant growth in metal-phthalic acid ester co-contaminated soils: A trial for reclamation and improvement of degraded soils. J. Environ. Manag. 2020, 261. [CrossRef] [PubMed]

48. Trenkel, M.E. Slow and Controlled-Release and Stabilized Fertilizers, 2nd ed.; International Fertilizer Industry Association (IFA): Paris, France, 2013.

49. Uchimiya, M.; Hiradate, S.; Antal, M.J. Dissolved phosphorus speciation of flash carbonization, slow pyrolysis, and fast pyrolysis biochars. ACS Sustain. Chem. Eng. 2015, 3, 1642-1649. [CrossRef]

50. Li, F.; Liang, X.; Niyungeko, C.; Sun, T.; Liu, F.; Arai, Y. Effects of Biochar Amendments on Soil Phosphorus Transformation in Agricultural Soils, 1st ed.; Elsevier Inc.: Amsterdam, The Netherlands, 2019. [CrossRef]

51. Qayyum, M.F.; Haider, G.; Iqbal, M.; Hameed, S.; Ahmad, N.; ur Rehman, M.Z.; Majeed, A.; Rizwan, M.; Ali, S. Effect of alkaline and chemically engineered biochar on soil properties and phosphorus bioavailability in maize. Chemosphere 2020, 266, 128980. [CrossRef]

52. De Figueiredo, C.C.; Pinheiro, T.D.; de Oliveira, L.E.Z.; de Araujo, A.S.; Coser, T.R.; Paz-Ferreiro, J. Direct and residual effect of biochar derived from biosolids on soil phosphorus pools: A four-year field assessment. Sci. Total Environ. 2020, 739, 140013. [CrossRef]

53. Shetty, R.; Vidya, C.S.N.; Prakash, N.B.; Lux, A.; Vaculík, M. Aluminum toxicity in plants and its possible mitigation in acid soils by biochar: A review. Sci. Total Environ. 2020, 142744. [CrossRef]

54. Gransee, A.; Führs, H. Magnesium mobility in soils as a challenge for soil and plant analysis, magnesium fertilization and root uptake under adverse growth conditions. Plant Soil 2013, 368, 5-21. [CrossRef]

55. Mikkelsen, R. Soil and fertilizer magnesium. Better Crop 2010, 94, 26-28. 